\title{
Chemical Variables and New Lamps in Phototherapy
}

\author{
Gerald Ente ${ }^{[37]}$, Edward W. Lanning, Peter Cukor, and Richard M. Klein \\ Department of Pediatrics, Nassau County Medical Center, East Meadow, New York, and The Bayside Research Center, \\ GTE Laboratories, Incorporated, Bayside, New York, USA
}

\begin{abstract}
Extract
In vitro studies were undertaken to measure the effects of varying concentrations of albumin and flux on the photodecomposition of bilirubin.

By using an experimental model, the effect of albumin on photodegradation of bilirubin was determined. Synthetic crystalline bilirubin solutions $(20 \mathrm{mg} / 100 \mathrm{ml}, \mathrm{pH}$ 7.4) were exposed to the same flux levels for periods of $4.5 \mathrm{hr}$. The only variable in this series was the concentration of albumin, ranging from 0.5 to $5 \mathrm{~g} / 100 \mathrm{ml}$. As the the concentration of albumin increased, the reaction rate decreased (Fig. 5).

The efficiency of phototherapy was studied by varying flux levels while maintaining other variables constant. Figure 6 shows a nonlinear relation between reaction rate and flux, in which higher flux levels resulted in less decomposition per amount of flux (i.e., efficiency). More than twice the flux level was required to attain a twofold increase in decomposition rate. The effect of light flux was such that continuous use of the lowest practical level is to be recommended.

Data are given on the comparison of the relative effectiveness of cool white, high intensity blue, and two experimental lamps. The four lamps were tested at conditions of constant distance and constant flux. The high intensity blue lamp was twice as effective as the cool white. The two experimental lamps showed a $17 \%$ increase over the blue lamp (Figs. 2 and 3 ).

The effect of time on the spectral output of the fluorescent lamps in an experimental model was determined by using a spectral radiometer. The energy dropoff within the 420 - to $480-\mathrm{nm}$ region at $200 \mathrm{hr}$ was approximately $20 \%$ for blue lamps and averaged $7.5 \%$ for the experimental lamps.
\end{abstract}

\section{Speculation}

As with any new drug used on the neonate, the effects of phototherapy must be categorized, and the procedure must be standardized. Further investigations are needed to determine exact in vivo decomposition products, optimal timing of exposure, differences in skin attenuation, toxicity reactions, site of action, and photobiologic and photochemical alterations and interreactions.

\section{Introduction}

Successful treatment and prophylaxis of neonatal hyperbilirubinemia with phototherapy-the use of magnetic waves of visible light-have been reported by many investigators in this country and abroad over the past 13 years $[1-5,9-14,18,19,24,25,27,28,30]$. Many questions regarding the physical hazards of phototherapy have been posed by investigators who have observed harmful effects produced in animals after ex- 
Table $I$. Definitions

\begin{tabular}{|c|c|}
\hline Flux & $\begin{array}{l}\text { Quantity of total radiant power or energy, } \\
\text { watts } / \mathrm{cm}^{2}\end{array}$ \\
\hline Lumen & $\begin{array}{l}\text { A unit of luminous flux, i.e., the capacity } \\
\text { to produce a visual sensation }\end{array}$ \\
\hline Footcandle & $\begin{array}{l}\text { A standard unit of illumination (1 lumen/ } \\
\text { sq foot) }\end{array}$ \\
\hline Nanometer & Unit of wavelength $10^{-9}$ meter \\
\hline Millimicron & Unit of wavelength $10^{-9}$ meter \\
\hline Angstrom & Unit of wavelength $10^{-10}$ meter \\
\hline Efficiency & $\begin{array}{l}\text { (Percentage decomposition/unit time)/ } \\
\text { (unit flux) }\end{array}$ \\
\hline Phosphor & $\begin{array}{l}\text { A substance which emits light when ex- } \\
\text { cited by radiation }\end{array}$ \\
\hline $\begin{array}{l}\text { Emission spec- } \\
\text { trum }\end{array}$ & $\begin{array}{l}\text { Radiant energy as a function of wave- } \\
\text { length }\end{array}$ \\
\hline
\end{tabular}

posure to high intensity radiation $[6,8,15,20,26]$. Other obstacles to the wider acceptance of phototherapy are attributable to the complexity of evaluating the in vivo system and the difficulty of extrapolating laboratory results to the clinical situation $[2,9,10,17$, $19,21,22,25,28]$.

The in vitro studies reported herein were designed to measure the effects of variations in concentrations of albumin and flux (see Table I) upon the photodecomposition of bilirubin. Also, experimental lamps were tested.

\section{Materials and Methods}

\section{Apparatus}

A light exposure box was built which allowed simultaneous exposure of three solutions by three different lamps. A Reeder thermopile [31] was used to measure the total flux (watts per square centimeter) of each lamp. The response of the thermopile is linear within $2 \%$ over the entire visible portion of the spectrum. One-millimeter precision cells [32] were used to expose solutions to lamps as well as to measure absorption spectra. Absorption spectra were obtained with a Cary model no. 14 recording spectrophotometer [33].

The lamps utilized in the tests consisted of two commonly used lamps, the cool white (GE F20T12CW) and high intensity blue (GE F20T12B), and two experimental lamps, $A$ and $B$ (Fig. 1). Lamp $A$ was phosphor no. L7352 [16] and Lamp $B$ was no. FPB 533C [23].

\section{Reagents}

Standard phosphate buffer ( $\mathrm{pH}$ 7.4) was prepared according to the method of White et al. [29]. Crystal- line unconjugated bilirubin [34] and crystallized human albumin [34] were used. Bilirubin was routinely recrystallized from methanol-chloroform solution. The first batch was subjected to ascending thin layer chromatographic analysis on silica gel plates, and no separated impurity spots were observed. The infrared spectrum of bilirubin prepared in this manner was obtained in a potassium bromide pellet. The spectrum showed only those bands assigned to bilirubin. After the pellet was exposed to daylight for several days, its spectrum showed no significant change. In this manner, it was established that bilirubin in a solid dry state was relatively insensitive to light. Test solutions were prepared by dissolving the appropriate amount of bilirubin in a minimum amount of $0.1 \mathrm{~N}$ sodium hydroxide solution. Albumin was added and the volume was adjusted with phosphate buffer. Bilirubin concentration ranged from 7.5 to $30 \mathrm{mg} / 100 \mathrm{ml}$ and albumin concentration from 0.05 to $5.0 \mathrm{~g} / 100 \mathrm{ml}$.

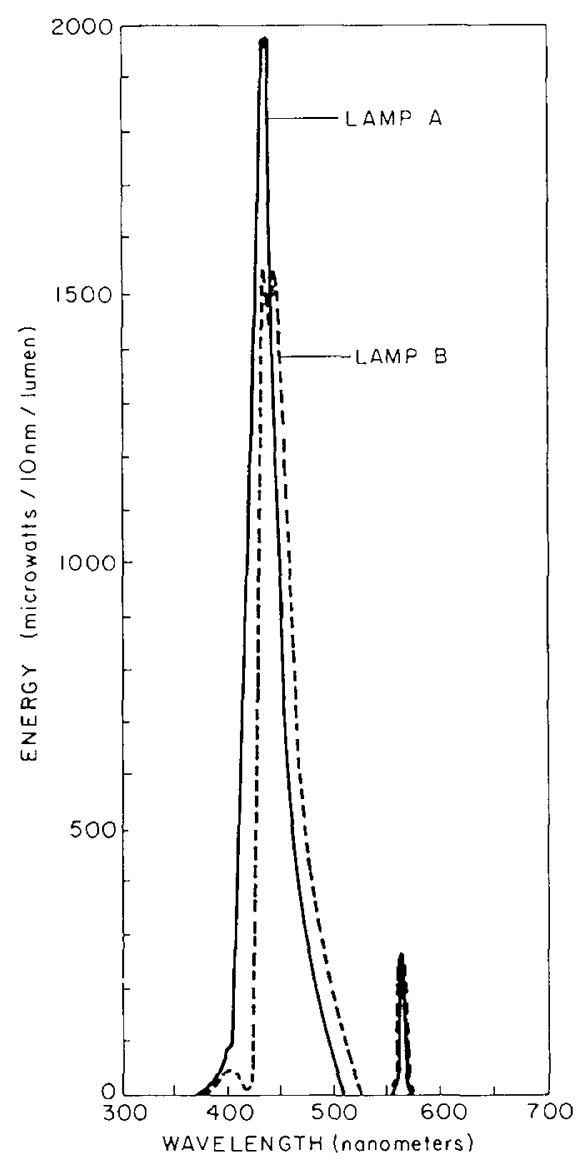

Fig. 1. Emission spectra for experimental lamps. Lamp $A$ is an alkaline earth pyrophosphate. $\operatorname{Lamp} B$ is a strontium chlorophosphate. 


\section{Test Procedure}

In the light exposure tests, portions of the test solutions were transferred to the I-mm cells, and their absorption spectra were recorded. The cells were then placed in the light exposure box for irradiation by the appropriate lamps. Each sample was placed at a distance from the lamp which provided the desired flux as measured with the thermopile at the front surface of the cell, except for those runs in which constant distance was employed. The lamp to sample distance varied from approximately 3 to 18 inches. Concurrently, a reference sample was prepared for monitoring any dark reaction. Periodically, the absorption spectra were obtained for both the test and reference samples in order to measure the bilirubin absorption as well as to observe any change in spectral shape. No temperature changes were observed.

In order to measure the relative effectiveness of the different lamps, samples of synthetic icteric serum were exposed to radiation from each. The concentration of bilirubin at any given time was inferred from the absorbance at $455 \mathrm{~nm}$, and the rate of decomposition was measured by the decrease in absorbance at this wavelength. The lamps were tested under conditions of constant distance and constant flux.

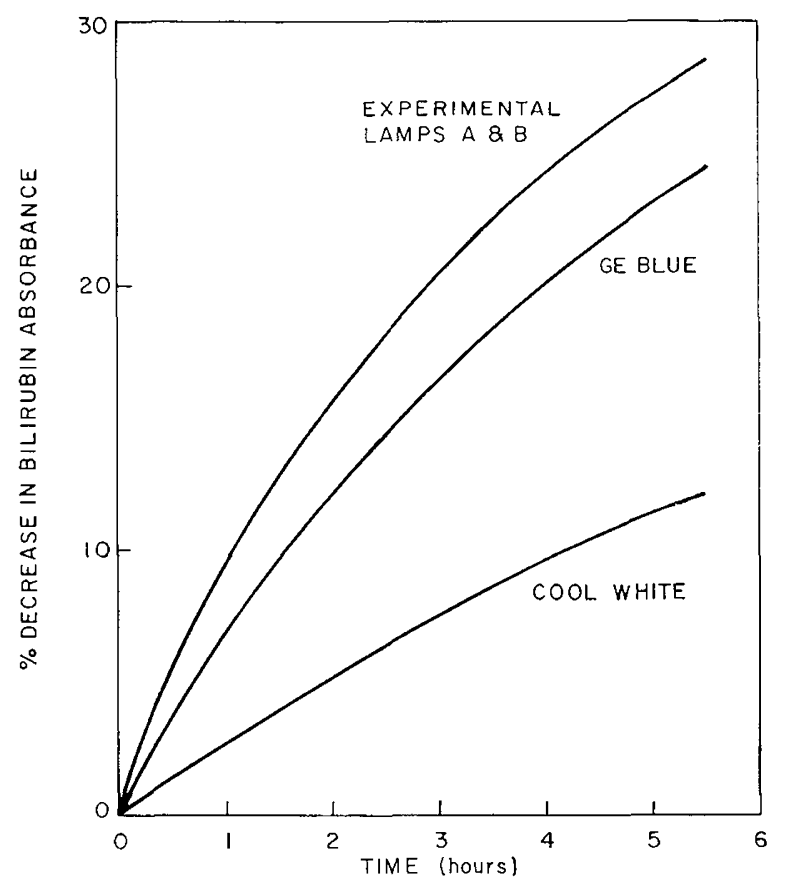

Fig. 2. Reaction rates for different lamps at constant flux. The experimental lamps are $17 \%$ more effective than the high intensity blue lamps used in clinical phototherapy. Cool white fluorescent lamps are only half as efficient as the high intensity blue.
To ascertain the effect of albumin on photodegradation of bilirubin, $20 \mathrm{mg} / 100 \mathrm{ml}$ solutions of bilirubin were exposed at $\mathrm{pH} 7.4$ for periods of $4.5 \mathrm{hr}$ to the same flux levels. The only variable in this series was the amount of albumin.

Finally, a series of tests was made to determine the effect of varying flux levels while maintaining all other factors constant.

To measure the effect of time on the spectral output of the fluorescent lamps, the maintenance of the four lamps was tested with a spectral radiometer. Light from a 4-inch section of the middle of the lamp was allowed to pass through a monochrometer to a photomultiplier. The output of the photomultiplier was digitized and fed to a computer that corrected the results for instrument spectral sensitivity. The computer then printed out the energy emitted by the lamp for each 2-nm interval. Blue, cool white, and two experimental lamps were measured with this equipment.

\section{Results}

Figure 2 compares results of bilirubin sample exposures to the four test lamps. Samples were so placed that the total light flux was constant. This show's that, after $5.5 \mathrm{hr}$ of irradiation, the high intensity blue lamp was twice as effective as the cool white. Moreover, the experimental lamps exhibited a $17 \%$ increase over the GE blue lamp.

In actual clinical use, lamps are placed at a fixed distance from the infant. A test run was therefore made under the conditions of constant lamp to sample distance. The results (Fig. 3) are quantitative differences which can be attributed to different lamp fluxes. For example, the blue lamp was 1.6 times as effective as the cool white, as contrasted to the factor of 2.0 found in the previous measurements. This is partially explained by the fact that at a fixed distance the flux level of the cool white was $10 \%$ greater than in the constant flux level experiments.

Figure 4 shows lamp maintenance data for a typical cool white lamp [35]. The percentages of initial output obtained after $100 \mathrm{hr}$ of operation for the two experimental lamps were $91 \%$ for $A$ and $94 \%$ for $B$. For the cool white lamp, the value was $96 \%$ and for the blue lamp the value was $85.7 \%$. The percentage of initial output for the blue lamp in the 420 - to 480 -nm region at $200 \mathrm{hr}$ was 80.9 , indicating a $20 \%$ dropoff at $200 \mathrm{hr}$. Moreover, the energy output after $200 \mathrm{hr}$ was constant for every $2-\mathrm{nm}$ reading within this interval.

Increasing albumin concentrations retarded the photodecomposition process. Figure 5 shows the effect of 


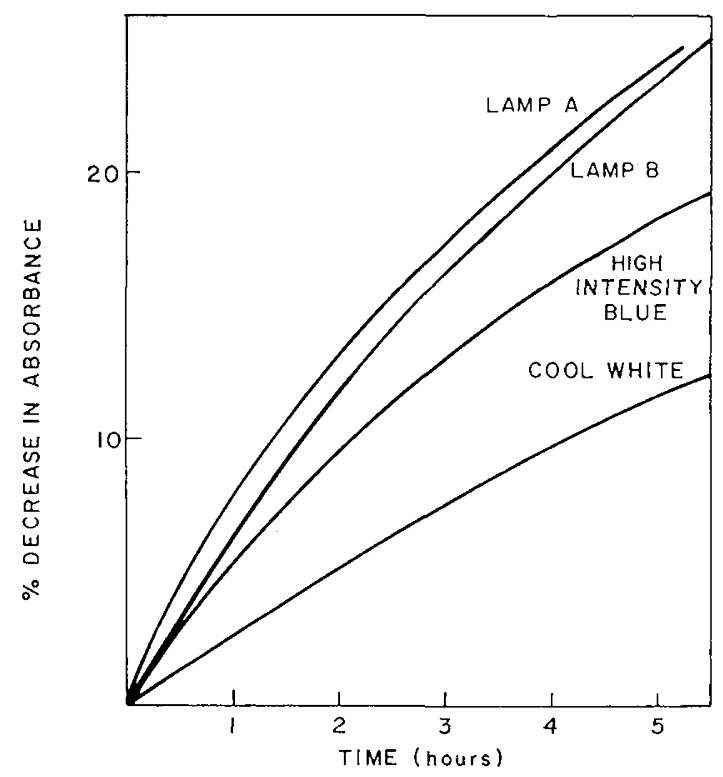

Fig. 3. Reaction rates for different lamps at constant distance. The experimental lamps are more efficient than high intensity bluc, and cool white lamps are the least efficient.

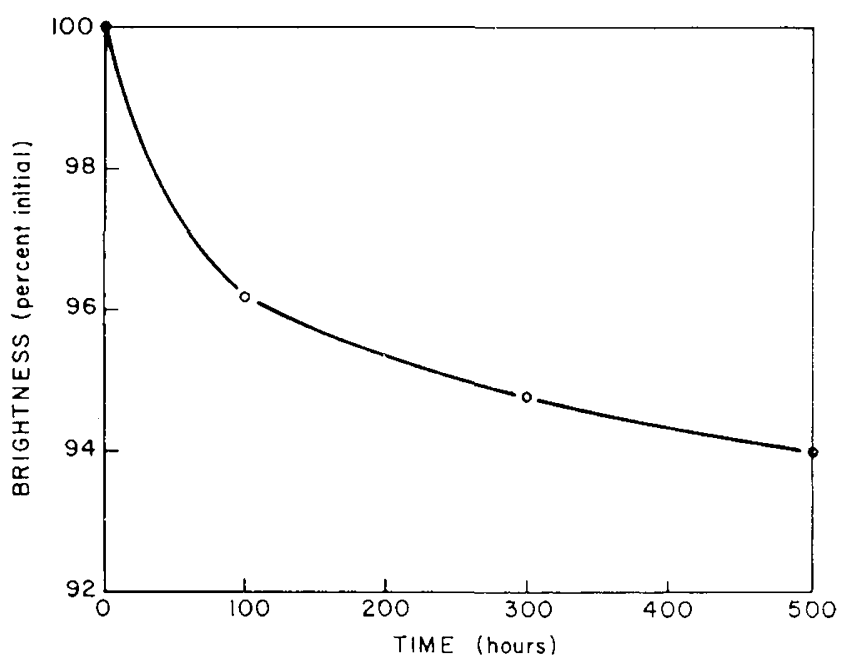

Fig. 4. Lamp maintenance. Phosphor decay curve for cool white lamps. Expeximental lamps exhibited $91 \%(\operatorname{lamp} A)$ and $94 \%$ (lamp $B$ ) of initial brightness after $100 \mathrm{hr}$. The curve approached an asymptote. This suggests a lamp lifetime of several thousand hours.

increasing albumin on the reaction rate of bilirubin at $\mathrm{pH}$ 7.4. As the concentration of albumin was increased, the reaction rate decreased. Beyond $4 \mathrm{~g} / 100$ $\mathrm{ml}$ albumin, little reduction in reaction rate was observed.

Figure 6 shows a nonlinear relation between reaction rate and flux in which higher flux levels resulted in less decomposition per unit flux. The lower the flux level, the higher was the efficiency of the system. One implication of Figure 6 is that the most efficient use of phototherapy is with the use of the lowest possible flux level necessary to maintain the desired bilirubin concentration. It is further suggested that continuous exposure is preferable to the intermittent mode.

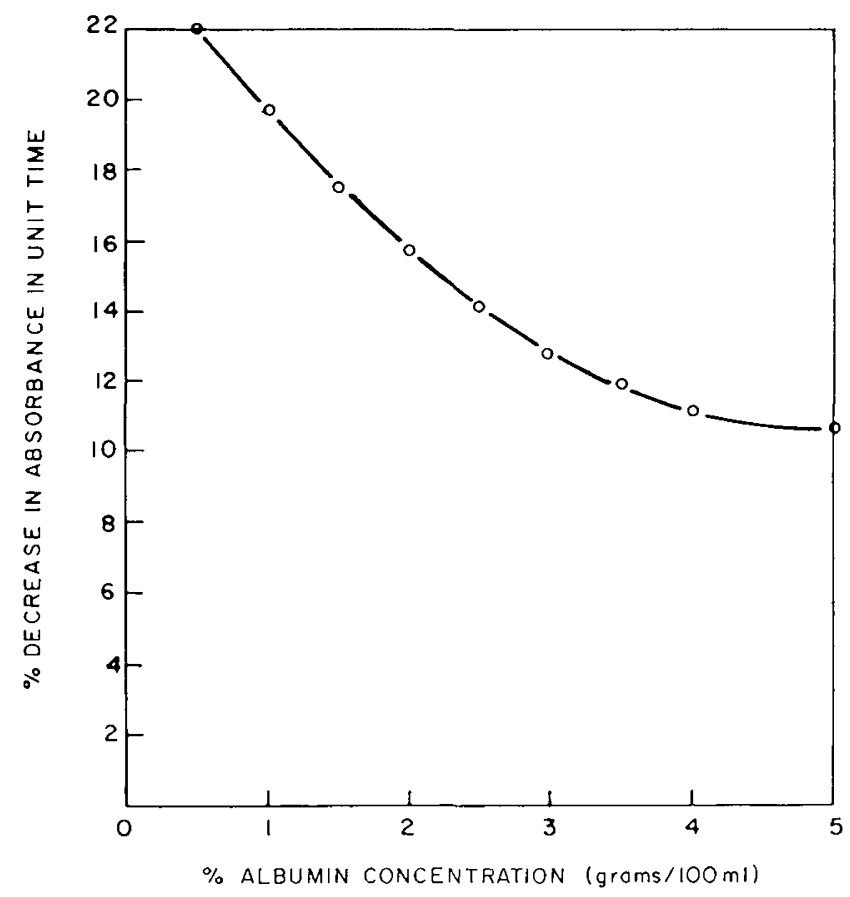

Fig. 5. Decomposition rate as a function of albumin concentration. As the concentration of albumin increases, photodecomposition rates decrease, i.e., the efficiency is lowered.

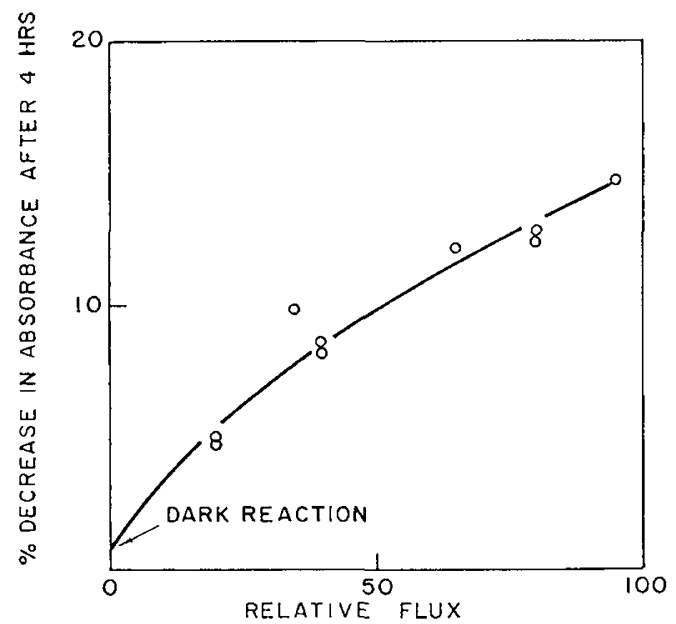

Fig. 6. Decomposition as a function of flux: the lower the flux level, the higher the efficiency (percentage of decomposition per unit flux). 


\section{Discussion}

The ideal lamp for phototherapy is one that exhibits all of its emission between 450 and $460 \mathrm{~nm}$. However, practical fluorescent lamps emit bands of greater than 10-nm width. The broad spectrum cool white lamp exhibits most of its phosphor emission between 500 and $700 \mathrm{~nm}$. The blue lamp emits maximal energy at $450 \mathrm{~nm}$ and is more suitable. Confusion occurs here because we are not concerned with footcandles or Iumens (see Table I), but are interested in the actual specific energy, which is measured in microwatts per square centimeter, or flux, for the specific nanometers or wavelengths involved in the process of photodecomposition of bilirubin. So, although a cool white bulb gives a higher footcandle reading on a light meter, it lacks flux comparable to the blue lamp. Again, the blue bulb gives a lower footcandle reading and emits a high relative energy concentration in the 420 - to 480 nm zone.

Seeking effective narrow band phosphors, we selected two phosphor systems (Fig. I). Most of their energy output was found to be in the desired wavelength region and their peak emissions were 4-5 times as great as that of the blue lamp.

The spectral output of all fluorescent lamps decreases as a function of time. The qualitative form of this deterioration is similar for all fluorescent lamps; i.e., phosphor decay is characterized by a relatively rapid dropoff in the first $100 \mathrm{hr}$, followed by a more gradual steady decline. The severity of the deterioration can therefore be judged by the amount of deterioration at $100 \mathrm{hr}$. For example, Figure 4 shows a lamp maintenance curve for a cool white lamp [35]. The shape of this curve is similar for all fluorescent lamps; that is, the brightness approaches an asymptote. The percentage of initial output obtained after $100 \mathrm{hr}$ of operation for the two experimental lamps (91\% for $A$ and $94 \%$ for $B$ ) indicates that the lamps will have a very long life (thousands of hours) under normal operating conditions.

Because of the long predicted lifetime of the experimental lamps as compared with that found by Sisson et al. [28] for the presently used blue lamps, the maintenance of these lamps was tested. Our data showed only a $10 \%$ dropoff in spectral output at 200 $\mathrm{hr}$, as opposed to $44 \%$ reported by Sisson et al. [28].

Varying concentrations of albumin were investigated. One mole albumin is capable of binding two moles of bilirubin under our experimental conditions [21]. Since the molecular weights are in the ratio of $\simeq$
$100 / 1,100 \mathrm{ml}$ of $1 \%$ solution of albumin is sufficient for binding $20 \mathrm{mg}$ bilirubin. Figure 5 shows the effect of increasing albumin on the reaction rate of bilirubin. Apparently, the albumin-bound bilirubin complex is more stable than free bilirubin, so that, as the concentration of albumin is increased, the reaction rate decreases. This result shows that although more albumin is desirable because of increased binding of bilirubin, which prevents deposition in tissue, it is disadvantageous in that it retards the rate of photodecomposition.

We studied the efficiency of phototherapy by varying flux levels while maintaining all other factors constant. Efficiency is defined as (percentage bilirubin decomposed per unit of time)/(total light flux). The lamps having the greatest efficiency will therefore theoretically accomplish the destruction of bilirubin with the least exposure of total radiation to the infant. The nonlinear relation between increasing flux and bilirubin decomposition as shown in Figure 6 means that higher flux levels result in less decomposition per unit flux. One implication of Figure 6 is that the most efficient use of phototherapy is the use of the lowest possible flux level necessary to maintain the desired bilirubin concentration. It is further suggested that continuous exposure is preferable to an intermittent mode. With intermittent use, light might be on for 2 hr and off for $2 \mathrm{hr}$. The "on" period must produce the same amount of decomposition as $4 \mathrm{hr}$ of continuous exposure. In order to achieve this, twice the decomposition rate must be attained. Figure 6 shows that much more than twice the flux level is required to attain a twofold increase in decomposition rate. Thus, the intermittent mode of therapy would require exposure to much more light. The effect of light flux is such that the lowest practical level is recommended. Moreover, continuous exposure is recommended to provide more efficient decomposition per unit of flux. Clinically, this was confirmed by Jurado-Garcia [13].

\section{Conclusions}

The experimental lamps, chosen on the basis of their emission spectra, are found to be 15-20\% more effective than the high intensity blue lamps used in clinical phototherapy. Cool white fluorescent lamps are found to be only half as efficient as the blue lamps. These results are similar regardless of albumin, flux, or bilirubin level. Increasing albumin concentration retards the photodecomposition process. The effect of light flux is such that continuous exposure at the lowest practical level is recommended. 


\section{References and Notes}

1. Behrman, R. E.: Phototherapy and hyperbilirubinemia. J. Pediat., 74: 989 (1969).

2. Behrman, R. E., and Hsia, D. Y. Y.: Summary of symposium on phototherapy for hyperbilirubinemia. J. Pediat., 75: 718 (1969).

3. Broughton, P. M. G., Rossiter, E. J. R., Warren, C. B. M., Goulis, G., AND LoRd, P. S.: Effect of blue light on hyperbilirubinemia. Arch. Dis. Childhood, 40: 666 (1965).

4. Callahan, E. W., Jr., Thaler, M. M., Karon, M., Bauer, K., AND Schmid, R.: Phototherapy of severe unconjugated hyperbilirubinemia: formation and removal of labeled bilirubin derivatives. Pediatrics, 46: 841 (1970).

5. Cremer, R. J., Perryman, P. W., and Richards, D. H.: Influence of light on the hyperbilirubinemia of infants. Lancet, $i$ : 1094 (1958).

6. Dantzker, D. R., AND Gerstein, D. D.: Retinal vascular changes following toxic effects on visual cells and pigment epithelium. Arch. Ophthalmol., 81: 106 (1969).

7. ENTE, G.: Relationship of phototherapy and skin color. J Pediat., 77: 1098 (1970).

8. ENTE, G., AND Klein, S. W.: Hazards of phototherapy. New Engl. J. Med., 283: 544 (1970).

9. ENTE, G., AND Pochedly, C.: Phototherapy for hyperbilirubinemia. Mcadowbrook Staff J., 1: 99 (1968).

10. Grunta, F., And Rath, J.: Effect of environmental illumination in prevention of hyperbilirubinemia of prematurity. Pediatrics, 44: 162 (1969).

11. Gorodischer, R., Levy, G., Krasner, J., and Yaffe, S.: Congenital nonobstructive nonhemolytic jaundice effect of phototherapy. New Engl. J. Med., 282: 375 (1970).

12. Hodgman, J. E., And Schwartz, A.: Phototherapy and hyperbilirubinemia of the premature. Amer. J. Dis. Child., 119: 473 (1970).

13. Jurado-Garcia, E., Grisard, N., Moreno Ruiz, M. E., Alvares de los Cobos, J., Jiminez, S. C., and Benssosen, S. D.: Phototherapy in the management of nconatal hyperbilirubinemia. Bol. Med. Hosp. Infant. Mex., 2\%: 141 (1970).

14. Karon, M., Imach, D., and Schwartz, A.: Effect of phototherapy in congenital nonobstructive nonhemolytic jaundice. New Engl. J. Med., 282: 377 (1970).

15. Kuwabara, J., AND GoRn, R. A.: Retinal damage by visible light. Arch. Ophthalmol., 79: 69 (1968).

16. LAgos, C. C.: Luminescence of divalent curopium in Ba-Ca, $\mathrm{Ba}-\mathrm{Sr}$, and $\mathrm{Ca}-\mathrm{Sr}$ orthophosphate and pyrophosphate compositions. J. Electrochem. Soc., 117: 1189 (1970).

17. LAIDler, K.: Chemical Kinetics, p. 15. (McGraw-Hill, New York, 1950).

18. LucEY, J. F.: Current status of phototherapy. Presented at Meeting of American Academy of Pediatrics, Chicago, Ill., 1969.
19. Lucey, J., Ferreiro, M., ANd Hewitt, J.: Prevention of hyperbilirubinemia of prematurity by phototherapy. Pediattrics, 41: 1047 (1968).

20. Noell, W. K., Walker, V. S., Kang, B. S., and Berman, S.: Retinal damage by light on rats. Invest. Ophthalmol., 5: 45 (1966).

21. ODELL, G. B.: The dissociation of bilirubin from albumin and its clinical implications. J. Pediat., 55: 268 (1959).

22. Ostrow, J. D., and Branham, R. V.: Photodecomposition of bilirubin and biliverdin in vitro. Gastroenterology, 58: 15 (1970).

23. Palilla, F. C., ANd O'Reilly, B. E.: Alkaline earth halophosphate phosphors activated by divalent europium. J. Electrochem. Soc., 115: 1076 (1968).

24. Porto, S. O., AND HsIA, D. Y. Y.: Mechanisms of blue light therapy in neonatal jaundice. J. Pediat., 74: 812 (1969).

25. Porto, S. O., Pildes, R. S., and Goodman, H.: Studies on the effect of phototherapy on neonatal hyperbilirubinemia on low birth weight infants. I. Skin color. J. Pediat., 75: 1045 (1969).

26. Sisson, T. R. C., Glauser, S. G., Glauser, E. M., Tasman, W., AND Kuwabara, T.: Retinal changes produced by phototherapy. J. Pediat., 77: 221 (1970).

27. Sisson, T. R. C., Kendall, N., Davies, R. E., And Berger, D.: Photobiologic effects of hyperbilirubinemia. Presented at Meeting of American Pediatric Society, Atlantic City, N. J., 1969.

28. Sisson, T. R. C., Kendall, N., Davies, R. E., and Berger, D.: Factors influencing the effectiveness of phototherapy. Symposium on Neonatal Bilirubin Metabolism. Original Article Series, Vol. 6, No. 2. (The National Foundation, New York, 1969).

29. White, D., Haidar, G., and Reinhold, J.: Spectrophotometric measurement of bilirubin concentration in the serum of the newborn by the use of a microcapillary method. Clin. Chem., 4: 211 (1958).

30. Yasunaga, S., Rudolph, A. J., and Felemovicius, L.: Comparative study of the effects of different fluorescent lights in phototherapy (in press).

31. C. M. Reeder Company, Detroit, Mich.

32. Catalogue type $37 Q$ from Precision Cells, Inc., Hicksville, N. Y.

33. Cary Instruments, Monrovia, Calif.

34. Mann Research Laboratories, Orangeburg, N. J.

35. Sylvania Electric Products, Inc., Mountain View, Calif.

36. The authors wish to thank Jorge Flores for carrying out experimental work, James Kranick for apparatus design, Robert Rubino for computer calculations, and Costas Lagos for lamp maintenance data.

37. Requests for reprints should be addressed to: Gerald ENTE, M.D., Department of Pediatrics, Nassau County Medical Center, East Meadow, N. Y. 11554 (USA).

38. Accepted for publication September 2, 1971. 